\title{
High Protein Gluten Free Snack Foods Based on Whole Grain Flour and Vegetables
}

\author{
Talwinder S. Kahlon, Ronald P. Haff, Jenny L. Brichta \\ Western Regional Research Center, USDA-ARS, Albany, CA, USA \\ Email: Talwinder.Kahlon@usda.gov
}

How to cite this paper: Kahlon, T.S., Haff, R.P. and Brichta, J.L. (2021) High Protein Gluten Free Snack Foods Based on Whole Grain Flour and Vegetables. Food and Nutrition Sciences, 12, 407-417. https://doi.org/10.4236/fns.2021.125031

Received: January 20, 2021

Accepted: May 8, 2021

Published: May 11, 2021

Copyright $\odot 2021$ by author(s) and Scientific Research Publishing Inc. This work is licensed under the Creative Commons Attribution International License (CC BY 4.0).

http://creativecommons.org/licenses/by/4.0/

(c) (i) Open Access

\begin{abstract}
Novel snack foods comprised of various combinations of whole grains and vegetables were evaluated for consumer acceptability in sensory booths by seventy-one in-house volunteers. Specifically, snacks containing Buckwheat (B), Buckwheat + Peanut meal + Kale (BPK), Sorghum + Peanut meal + Okra (SPO), and Sorghum + Peanut meal + Okra + Jalapeno (SPOJ) were judged for appearance, aroma, flavor and texture on a scale from one to five, as well as on overall acceptability on a binary scale. Several combinations of ingredients were evaluated, with the final composition of snacks tested decided by consensus of laboratory personnel based on criteria of expected consumer acceptability of $70 \%$. While all snacks were found to be statistically similar for appearance, aroma, and flavor, the texture of BWPK and SPO were rated significantly equal and more favorable than $\mathrm{BW}$ and SPOJ. Acceptability ratings were generally high; SPOJ (94\%), BPK (93\%), SPO (89\%), and B (85\%), with no significant difference, observed between SPOJ and BPK $(\mathrm{p}=0.05)$. The snack foods evaluated are higher (up to triple) in protein, lower (as low as half) in fat, are gluten-free with no added sugar, and generally higher in nutritional content as compared to most traditional snack foods. While ideally suited for commercial production, these snacks can also be easily prepared at home with minimal equipment requirements, thus offering a healthy alternative for all consumers including vegetarians, vegans, and those hypersensitive to gluten.
\end{abstract}

\section{Keywords}

Buckwheat, Gluten-Free, Jalapeno, Kale, Okra, Peanut Meal, Sorghum

\section{Introduction}

Americans are increasingly aware of and alarmed by the consequences of obesity. In one recent survey, 81 percent of Americans ranked obesity as the nation's 
number one health problem, followed by cancer, diabetes, and heart disease, and $94 \%$ believe that obesity increases the risk for early death even in the absence of other underlying conditions [1]. In fact, obesity is associated with an increased risk for type 2 diabetes, high blood pressure, stroke, and many types of cancers. Specifically, obesity has been correlated with doubling heart disease and stroke and a 1.5-fold increase in mortality [2]. Obesity has also been identified as one of the underlying conditions associated with serious COVID-19 symptoms and poor outcomes [3]. Despite increased awareness, the obesity epidemic shows no sign of slowing, and the national adult obesity rate has increased by 26 percent since 2008 , with over $40 \%$ of adults and roughly $18 \%$ of children classified as obese [3]. Globally, roughly $10 \%$ of men and $14 \%$ of women are obese, double the rate in 1980 [4]. At the simplest level, obesity is caused by energy intake exceeding energy expenditure, suggesting that diet and physical activity are critical factors for controlling body weight [5]. While excess consumption of fat, simple sugars and salt have all been correlated with obesity, the debate over nutritional strategies for weight control is far from settled. Studies have suggested that diets with more than $35 \%$ of calories derived from fat lead to obesity [6]; others point the finger at excess consumption of simple carbohydrates, especially sugars [7]. Average daily US sugar consumption has reached 84 grams (20 teaspoons) whereas the American Heart Association recommends 25 grams for women and 38 for men [8]. Research has linked sugar consumption with excess body weight, also a greater risk of dying from heart disease [8]. Of course, dietary factors can have far-reaching consequences to health beyond obesity. Diets high in fat have been associated with increased blood cholesterol and an increased risk of heart disease and cancer [9] [10]. The consumption of saturated fat is linked to elevated LDL with increased incidence of atherosclerosis and stroke [11]. Excessive salt intake has long been implicated in hypertension and cardiovascular disease and has recently been associated with obesity, insulin resistance, and metabolic syndrome. Consequently, the American Heart Association has called for reducing salt intake recommendations to $1500 \mathrm{mg} /$ day; however, most adults consume more than $3400 \mathrm{mg}$ [12]. Thus, a critical tool for addressing obesity and related diseases involves proper nutrition i.e. properly balanced consumption of fat, salt, carbohydrates and protein, among others, and indeed federal guidelines for healthy nutrition call for limiting calories from added sugars and saturated fats and reducing sodium intake. Studies have indicated that approximately one-third of calories are obtained through snacking between meals, with many snacks providing high energy and low nutrition i.e. added sugars and saturated fats [13]. Thus, snacking is likely to be a major factor in the obesity epidemic. However, it is also reported that snacks with high nutritional content contribute to satiety and can prevent overeating during meals, thus combatting obesity. It has been reported that snacks higher in protein, compared with carbohydrate or fat had the strongest satiety effect [14]. In general, whole foods high in protein, fiber, and whole grains are most likely to promote satiety when consumed as snacks. USDA nutritional guidelines recommend that at least $50 \%$ of grain consumption 
should comprise whole grains, as opposed to processed grains in which the removal of bran results in loss of nutritional content as well as fiber [15]. Complex carbohydrates in whole grains have been associated with reduced risk of obesity and related disease. For instance, while some recent research suggests that lowcarbohydrate diets promote weight loss and healthy aging [16] [17], it has also been observed that the risk of heart disease was significantly lower with the consumption of whole-grain rye and oats [18]. Along with obesity and related diseases, the incidence and awareness of certain food sensitivities/allergies have been increasing in recent decades, including non-celiac gluten sensitivity [19] [20]. In fact, although gluten sensitivity was only first clinically identified in 1980 , gluten-free food has become increasingly popular. In 2015, $20 \%$ of Americans polled claimed a gluten-free diet [21]. Sales of gluten-free foods were projected to top $\$ 2$ billion in 2020, up nearly $\$ 400$ million from 2015 [22], even though less than one percent of the population has celiac disease. Gluten sensitivity impedes proper intestinal absorption of nutrients for celiac patients as well as gluten-sensitive individuals [20] [23].

Given the high percentage of calories consumed as snacks between regular meals and the poor nutritional content of most consumed snacks, the development of alternative snack foods that satisfy the consumer's snacking needs and desires while providing nutritional content and satiety is critical as one tool to combat obesity and obesity-related diseases. The objective of this study was to investigate basic ingredients with required nutritional qualities (i.e. whole grains and vegetables) as the basis for alternatives to most traditional snack foods and test the resulting products for consumer acceptability. The developed snacks should be whole grain, low fat, high protein ( $>25 \%$ ), gluten-free, no added sugar or salt and score at least 70\% acceptability in sensory panel evaluations.

\section{Materials and Methods}

\subsection{Overview}

Novel snack foods comprised of various combinations of whole grains and vegetables with desirable nutritional characteristics were evaluated for consumer acceptability in sensory booths. Specifically, snacks containing Buckwheat (B), Buckwheat + Peanut meal + Kale (BPK), Sorghum + Peanut meal + Okra (SPO), and Sorghum + Peanut meal + Okra + Jalapeno (SPOJ) were judged for appearance, aroma, flavor and texture and overall acceptability. Nutritional content of resulting products was evaluated and compared to certain widely consumed traditional snack foods.

\subsection{Ingredients}

Buckwheat (Fagopyrum esculentum) is a type of grain that doesn't grow on grasses but is processed similarly to cereals. It is gluten-free, a good source of fiber, and rich in minerals and various plant compounds. Health benefits associated with buckwheat consumption include hypertension/cholesterol reduction, neuropro- 
tection, as well as anti-cancer, inflammatory and diabetic effects [24] [25]. Buckwheat is high in protein $(16 \%-18 \%)$, with a high biological value (90\%) suggesting that its protein contains the amino acids needed to form proteins required by the human body [26] [27]. One cup (155 g) of buckwheat provides $34 \%$ of recommended daily intake of manganese, $28 \%$ of copper, $21 \%$ of magnesium, $18 \%$ of dietary fiber and $17 \%$ of phosphorus.

Sorghum (Sorghum bicolor), is a drought-tolerant grass species whose grain is used for food, feed, and ethanol production [28]. In the United States, human consumption of sorghum is increasing due to its rich nutritional content [29]. Sorghum is gluten-free rich in complex carbohydrates, moderate in protein, low in fat, and fiber-rich. It is also a good source of many vitamins and essential elements, including potassium, thiamin, riboflavin, niacin, pyridoxine, folate, pantothenic acid, vitamin E, iron, zinc, magnesium, and phosphorus. It also contains health-promoting phytochemicals, like lignans, phenolic acids, phytic acid, plant sterols and saponins [30].

Peanut meal, the low-value by-product of peanut oil extraction, is a high protein product widely used as livestock feed. Peanut meal is high in oleic and linoleic acids, dietary fiber, tocopherol, choline, and multiple vitamins including thiamine, riboflavin, niacin, pyridoxine, and folic acid [31].

Kale (Brassica oleracea) is a leafy green member of the cabbage family which contains no fat or cholesterol and is low in sodium. It is rich in lutein, flavonoids and polyphenols [32], as well as sulforaphane which have been associated with cancer prevention [33]. In addition, it is a good source of vitamins A, C and $\mathrm{K}$ [15]. These nutritional benefits have resulted in increased consumer demand and production.

Okra (Abelmoschus esculentus) is a vegetable rich in soluble fiber, which has been shown to lower cholesterol [34]. Okra has been suggested as a potential tool to mitigate malnutrition and food insecurity [35]. Okra binds bile acids leading to reduced fat absorption and lower cholesterol [36]. Okra is high in dietary fiber, polyphenols and many vitamins and minerals, including vitamin $\mathrm{C}$ and Vitamin $\mathrm{K}$, and has moderate levels of thiamin, folate and magnesium [35].

Jalapeno (Capsicum annuum) peppers are a good source of phenolics, ascorbic acid, and capsaicin and have high antioxidant activity [37]. Capsaicin, a thermogenic chemical, provides the "hotness" in peppers by increasing the metabolism of adipose tissue, stimulating fat burning and generating heat [38].

Guar gum (guaran) is a food binder (thickener) made from legumes called guar beans. Guar gum is mainly composed of soluble fiber and has low protein content, typically three to five percent. It is commonly used when baking with whole grain flours that typically don't rise due to their lack of gluten.

Ingredients were purchased from local food markets. Sorghum and buckwheat flours were prepared using a tabletop flour mill (Blendtec Kitchen Mill, Model 91) at medium setting (Blendtec Inc., Orem, UT). Peanut meal was produced by extracting oil using a heated Vepor Oil Press (Joyfay International, Cleveland, $\mathrm{OH}$ ). Okra and Jalapenos were chopped using a Mini-Prep Processor (Cuisinart, 
East Winsor, NJ 08520 USA). Buckwheat flour, sorghum flour, peanut meal, okra, jalapeno, and kale were analyzed for nitrogen using a Leco FP628 analyzer (Leco Corp., St Joseph, MI) with AOAC method 990.03 [39]. Crude fat was measured by Soxhlet extraction with petroleum ether using method 963.15, ash using method 923.03, and moisture using AOAC method 925.10 [40].

\subsection{Preparation of Snacks}

Snack dough was prepared using different combinations of the six basic ingredients listed in Table 1. For some doughs, guar gum was added as a binder to achieve appropriate consistency, along with water. Olive oil was added to some doughs to improve flavor. Preliminary analysis by laboratory personnel was conducted to select final dough compositions for trials based on dough consistency and cooked snack taste. Snack dough composition of the four selected combinations of ingredients is given in Table 2.

The prepared dough was set at room temperature for 30 minutes. Snacks were cooked using a commercially available cookie maker (Chef's Choice KrumKake Express 839, EdgeCraft Corporation, Avondale, PA) for two minutes at heat setting 4 (Range 1 - 6). Cooking surfaces were lightly sprayed with non-stick cooking spray (Pam, ConAgra Foods, Omaha, NE). $20 \mathrm{~g}$ of snack dough was placed in the center of the lower cooking surface and upper side was closed and locked. The cooking temperature ranged from $185^{\circ} \mathrm{C}-208^{\circ} \mathrm{C}$ as measured using an

Table 1. Proximate composition of snack ingredients, as is basis.

\begin{tabular}{cccccc}
\hline Ingredients & Protein & Fat & Minerals & Carbohydrate $^{* *}$ & Total (Dry Matter) \\
\hline Buckwheat & $16.30 \pm 0.12$ & $3.33 \pm 0.12$ & $2.97 \pm 0.01$ & $66.81 \pm 0.15$ & $89.41 \pm 0.11$ \\
Sorghum & $7.72 \pm 0.12$ & $6.25 \pm 0.33$ & $1.31 \pm 0.10$ & $73.78 \pm 0.28$ & $89.06 \pm 0.55$ \\
Peanut meal & $43.46 \pm 0.10$ & $16.34 \pm 0.07$ & $3.94 \pm 0.09$ & $30.13 \pm 0.07$ & $93.87 \pm 0.02$ \\
Okra & $2.71 \pm 0.02$ & $0.56 \pm 0.02$ & $0.92 \pm 0.02$ & $8.60 \pm 0.09$ & $12.79 \pm 0.26$ \\
Jalapeno & $1.23 \pm 0.03$ & $0.55 \pm 0.02$ & $0.62 \pm 0.02$ & $6.91 \pm 0.03$ & $9.31 \pm 0.09$ \\
Kale & $2.01 \pm 0.01$ & $0.90 \pm 0.01$ & $1.88 \pm 0.01$ & $9.00 \pm 0.01$ & $13.79 \pm 0.07$ \\
\hline
\end{tabular}

${ }^{\star}$ Nitrogen to protein factors used was $6.25 ;{ }^{*}$ Total carbohydrate $=100-($ crude protein + crude fat + ash + water).

Table 2. Dough composition.

\begin{tabular}{|c|c|c|c|c|c|c|c|c|c|c|}
\hline Snack & $\begin{array}{l}\text { Buckwheat } \\
\text { flour }\end{array}$ & $\begin{array}{l}\text { Sorghum } \\
\text { flour }\end{array}$ & $\begin{array}{c}\text { Peanut } \\
\text { meal }\end{array}$ & Okra & Jalapeno & Kale & $\begin{array}{l}\text { Olive } \\
\text { oil }\end{array}$ & $\begin{array}{l}\text { Guar } \\
\text { gum }\end{array}$ & Salt & $\begin{array}{l}\text { Water } \\
(\mathrm{ml})\end{array}$ \\
\hline $\mathrm{B}^{*}$ & 92 & - & - & - & - & - & 6 & 2 & - & 120 \\
\hline $\mathrm{BPK}^{\star *}$ & 24 & & 24 & & - & 48 & 4 & - & - & 100 \\
\hline $\mathrm{SPO}^{* * *}$ & - & 34 & 33 & 33 & - & - & - & - & - & 55 \\
\hline $\mathrm{SPOJ}^{* * * *}$ & - & 31 & 30 & 30 & 9 & - & - & - & - & 50 \\
\hline
\end{tabular}

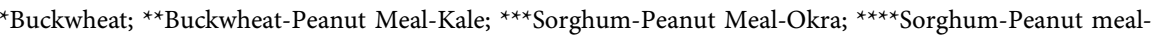
Okra-Jalapeno. 
infrared thermometer (Flute 61, Fluke Australia Pty Ltd., Baulkham Hills, NSW 2153). Cooked snacks were cooled to room temperature and sealed under nitrogen in Ziplock bags (SC Johnson Inc., Pleasanton, CA).

\subsection{Sensory Evaluation of Snacks}

Informed consent regarding snack ingredients and potential allergy issues was obtained from 71 volunteer tasters. Snacks were cut into four pieces with a pizza cutter and appropriately labelled by content ingredients for presentation to tasters. Tasters used water as palate cleanser between samples and evaluated snacks both individually and relative to each other in terms of preference. The volunteers sampled the snacks in sensory evaluation booths under white lights and scored them for the traits color, aroma, taste and texture ("mouth feel") on a scale of 1 - 5 (Like very much $=5$, like slightly $=4$, neutral $=3$, dislike slightly $=2$ and dislike very much $=1$ ) as well as overall acceptability on a binary scaly (acceptable (2) or unacceptable (1)). Scores' means were analyzed with Minitab software version 14.12.0 (Minitab Inc., State College, PA) using one-way analysis of variance and Tuckey's multiple comparison tests at the $\mathrm{p} \leq 0.05$ level of significance and interpreted for consumer acceptance by trait. Likeability for a particular trait was derived as $n^{\star}$ mean/max and compared between traits.

\section{Results and Discussion}

Table 3 reports the results of the sensory evaluations. Scores for color ranged from 4.22 - 4.42 (out of 5), aroma from 3.86 to 4.06, taste from 3.81 to 4.08 and texture from 3.72 to 4.2. No significant difference was observed in scores of color/appearance, odor/aroma, or taste/flavor for any of the snack formulations. However, differences were observed for texture, with scores falling into two groups of significance in which BPK and SPO were rated superior to SPOJ or BW. Likability scores by trait (across all snacks) indicated the highest likeability for color/ appearance (60 - 63), followed by odor/aroma (55 - 58), taste/flavor (54 - 56) and texture/mouth feel (53 - 60).

Of the 71 tasters, scores for acceptable were 67 (94\%), 66 (93\%), 63 (89\%) and $60(85 \%)$ for SPOJ, BPK, SPO and BW, respectively. Acceptability of the SPOJ and BPK snacks were similar and significantly higher than SPO, which in turn was significantly higher than BW. The aim of this study was acceptability greater than $70 \%$, in keeping with previously reported results for whole-grain gluten-free

Table 3. Sensory evaluation scores.*

\begin{tabular}{cccccc}
\hline Snack & Color/Appearance & Odor/Aroma & Taste/Flavor & Texture/Mouth feel & Acceptability \\
\hline BW & $4.22 \mathrm{a}$ & $4.01 \mathrm{a}$ & $3.81 \mathrm{a}$ & $3.72 \mathrm{~b}$ & $1.85 \mathrm{c}$ \\
BPK & $4.41 \mathrm{a}$ & $4.06 \mathrm{a}$ & $3.96 \mathrm{a}$ & $4.20 \mathrm{a}$ & $1.93 \mathrm{a}$ \\
SPO & $4.42 \mathrm{a}$ & $3.86 \mathrm{a}$ & $3.92 \mathrm{a}$ & $4.16 \mathrm{a}$ & $1.89 \mathrm{~b}$ \\
SPOJ & $4.32 \mathrm{a}$ & $3.94 \mathrm{a}$ & $4.08 \mathrm{a}$ & $3.93 \mathrm{~b}$ & $1.94 \mathrm{a}$ \\
\hline
\end{tabular}

${ }^{\star}$ Values within columns with different superscripts differ significantly $(\mathrm{p} \leq 0.05, \mathrm{n}=71$ ). 
buckwheat snacks [41]. The current study confirms that with appropriate modifications consumer acceptability of $85 \%-94 \%$ can be achieved in whole-grain, gluten-free high protein snacks.

Calculated nutritional content of the prepared snacks is shown in Table 4. Protein content of snacks containing peanut meal (BPK, SPO and SPOJ) all exceeded the $25 \%$ goal, while Buckwheat snacks without peanut meals were significantly lower at $17 \%$. Fat content ranged from $10 \%-17 \%$, and minerals from $3.1 \%$ - 4.7\%, with no added salt (Table 2).

In 2017, the top six snack food categories (Salty; Candy; Cheese; Cookies; Crackers; Ice Cream) generated about 87.5 billion dollars of retail sales in the U.S. [42]. Thus, for comparison to more traditional snack foods, the nutritional content of common products from each of these categories is shown in Table 5. With the exception of cheese, all are far below the $25 \%$ protein content of the developed snacks presented in Table 4, and with the exception of ice cream all are significantly higher in fat. Most importantly, while the snacks developed in this study contain no added sugar, many of the common snacks are loaded. A (snack) diet comprising a mean of the developed products would contain approximately three times the protein, half the fat, and none of the 21.3 percent sugar of the mean of the common popular snack food categories. Finally, the products presented in this study are gluten-free and contain no saturated fats.

In comparison with commonly eaten snacks such as those in Table 5, the snacks presented here to promote good health and are generally acceptable to consumers. These snacks can be made in any household kitchen using residential

Table 4. Composition of the prepared snacks (\%). Note that all contain no added sugar.

\begin{tabular}{ccccc}
\hline Snacks & Protein & Fat & Minerals & Carbohydrates \\
\hline BW & 17.00 & 10.27 & 3.09 & 69.64 \\
BPK & 28.03 & 16.76 & 4.69 & 50.52 \\
SPO & 27.53 & 11.83 & 3.15 & 57.49 \\
SPOJ & 27.33 & 11.75 & 3.2 & 57.72 \\
Mean & 25.0 & 12.7 & 3.5 & 58.8 \\
\hline
\end{tabular}

Table 5. Composition (\%) of common representatives of the top six snack food categories.

\begin{tabular}{ccccc}
\hline Brand & Protein & Fat & Carbohydrates & Sugar \\
\hline Lays Chips & 7.1 & 35.7 & 53.6 & 3.6 \\
Snickers & 6.8 & 23.9 & 59.6 & 51.1 \\
String Cheese & 25.0 & 21.4 & 0 & 0 \\
Oreos & $<3.4$ & 24.1 & 72.4 & 44.8 \\
Ritz & $<6.25$ & 25.0 & 62.5 & 6.25 \\
Ice Cream Sandwich & 4.7 & 9.3 & 37.2 & 22.1 \\
Mean & $<8.9$ & 21.7 & 47.6 & 21.3 \\
\hline
\end{tabular}

Composition given on product labels. 
countertop appliances or by commercial companies, and thus offer healthy nutritious snack alternatives for all groups of people including vegetarians, vegans and those hypersensitive to gluten.

\section{Conclusion}

Whole grain gluten-free high protein snacks based on flours of buckwheat and sorghum, peanut meal, kale, okra and jalapeno were sensory evaluated by seventy-one in-house volunteers. Consumer acceptability of snacks ranged from $94 \%$ (Buckwheat-Peanut meal-Kale) to 85\% (Buckwheat alone). Compared with commonly consumed products from the most popular categories of snack foods, the snacks developed here contain approximately three times the protein, half the fat, are gluten-free and contain no added sugar or salt. These snacks are healthful, nutritious, and tasty and can be prepared in any household kitchen using residential countertop appliances. These snacks offer healthy food for all including vegetarians, vegans and those hypersensitive to gluten.

\section{Conflicts of Interest}

The authors declare no conflicts of interest regarding the publication of this paper.

\section{References}

[1] Rosenthal, R.J., Morton, J., Brethauer, S., Mattar, S., De Maria, E., Benz, J.K., Titus, J. and Sterrett, D. (2017) Obesity in America. Surgery for Obesity and Related Diseases, 13, 1643-1650. https://doi.org/10.1016/j.soard.2017.08.002

[2] Engin, A. (2017) The Definition and Prevalence of Obesity and Metabolic Syndrome. In: Engin, A.B. and Engin, A., Eds., Obesity and Lipotoxicity Advances in Experimental Medicine and Biology, Vol. 960, Springer, Cham, 1-17. https://doi.org/10.1007/978-3-319-48382-5_1

[3] Centers for Disease Control and Prevention (CDC) (2020) Obesity, Race/Ethnicity, and COVID-19. https://www.cdc.gov/obesity/data/obesity-and-covid-19.html

[4] Harvard School of Public Health (2020) Adult Obesity: A Global Look at Rising Obesity Rates.

https://www.hsph.harvard.edu/obesity-prevention-source/obesity-trends/obesity-ra tes-worldwide

[5] Aronne, L.J., Nelinson, D.S. and Lillo, J.L. (2009) Obesity as a Disease State: A New Paradigm for Diagnosis and Treatment. Clinical Cornerstone, 9, 9-25. https://doi.org/10.1016/S1098-3597(09)80002-1

[6] Howarth, N.C., Huang, T.T.-K., Roberts, S.B. and McCrory, M.A. (2005) Dietary Fiber and Fat Are Associated with Excess Weight in Young and Middle-Aged US Adults. Journal of the American Dietetic Association, 105, 1365-1372. https://doi.org/10.1016/j.jada.2005.06.001

[7] Rippe, J.M. and Angelopoulos, T.J. (2016) Added Sugars and Risk Factors for Obesity, Diabetes, and Heart Disease. International Journal of Obesity, 40, 22-27. https://doi.org/10.1038/ijo.2016.10

[8] John Hopkins Medicine (2021) Obesity, Sugar and Heart Health. https://www.hopkinsmedicine.org/health/wellness-and-prevention/obesity-sugar-a 
$\underline{\text { nd-heart-health }}$

[9] Alsanea, S., Gao, M. and Liu, D. (2017) Phloretin Prevents High-Fat Diet Induced Obesity and Improves Metabolic Homeostasis. Journal of the American Association of Pharmaceutical Scientists, 19, 797-805.

https://doi.org/10.1208/s12248-017-0053-0

[10] Lu, M., Wan, Y., Yang, B., Huggins, C.E. and Li, D. (2018) Effects of Low-Fat Compared with High-Fat Diet on Cardiometabolic Indicators in People with Overweight and Obesity without Overt Metabolic Disturbance: A Systematic Review and Meta-Analysis of Randomized Controlled Trials. British Journal of Nutrition, 119, 96-108. https://doi.org/10.1017/S0007114517002902

[11] Sun, Y., Neelakantan, N., Wu, Y., Lote-Oke, R., Pan, A. and van Dam, R.M. (2015) Palm oil Consumption Increases LDL Cholesterol Compared with Vegetable Oils Low in Saturated Fat in a Meta-Analysis of Clinical Trials. Journal of Nutrition, 145, 1549-1558. https://doi.org/10.3945/jn.115.210575

[12] American Heart Association (2012) Salt of the Earth Reducing Sodium in the U.S. Diet. AHA/HPFS/02/2012.

https://www.heart.org/idc/groups/heart-public/@wcm/@adv/documents/downloada ble/ucm_304869.pdf

[13] Njike, V.Y., Smith, T.M., Shuval, O., Shuval, K., Edshteyn, I., Kalantari, V. and Yaroch, A.L. (2016) Snack Food, Satiety, and Weight. Advances in Nutrition, 7, 866-878. https://doi.org/10.3945/an.115.009340

[14] Chapelot, D. (2011) The Role of Snacking in Energy Balance: A Biobehavioral Approach. Journal of Nutrition, 141, 158-162. https://doi.org/10.3945/jn.109.114330

[15] USDA (2015) Nutrition Policy and Promotion; Dietary Guidelines for Americans. http://health.gov/dietaryguidelines/2015/guidelines

[16] Brown-Borg, H.M. (2017) Disentangling High Fat, Low Carb, and Healthy Aging. Cell Metabolism, 26, 458-459. https://doi.org/10.1016/j.cmet.2017.08.020

[17] Brouns, F. (2018) Overweight and Diabetes Prevention: Is a Low-CarbohydrateHigh-Fat Diet Recommendable? European Journal of Nutrition, 57, 1301-1312. https://doi.org/10.1007/s00394-018-1636-y

[18] Halnaes, A., Kyro, C., Anderson, I., Lacoppidan, S., Overvad, K., Christensen, J., Tjonneland, A. and Olsen, A. (2016) Intake of Whole Grains Is Associated with Lower Risk of Myocardial Infarction: The Danish Diet, Cancer and Health Cohort. American Journal of Clinical Nutrition, 103, 999-1007. https://doi.org/10.3945/ajcn.115.124271

[19] Biesiekierski, J.R., Newnham, E.D. and Shepherd, S.J. (2011) Self-Diagnosis of Non-Coeliac Gluten Intolerance by Australian Adults: Failure to Exclude Coeliac Disease or Benefit from a Gluten-Free Diet. Journal of Gastroenterology, 26, 70.

[20] Volta, U., Caio, G., Tovoli, F. and Giorgio, R.D. (2013) Non-Celiac Gluten Sensitivity: Questions Still to Be Answered Despite Increasing Awareness. Cellular \& Molecular Immunology, 10, 383-392. https://doi.org/10.1038/cmi.2013.28

[21] Riffkin, R. (2017) One in Five Americans Include Gluten-Free Foods in Diet. https://prezi.com/fuws7phgltkb/one-in-five-americans-include-gluten-free-foods-in -diet

[22] Packaged Foods (2020) Gluten Free Foods in the US. https://www.packagedfacts.com/Gluten-Free-Foods-10378213

[23] Lebwohl, B., Ludvigsson, J.F. and Green, P.H. (2015) Celiac Disease and Non-Celiac Gluten Sensitivity. British Medical Journal, 351, 4347. 
https://doi.org/10.1136/bmj.h4347

[24] Lloyd-Jones, D.M., Hong, J., Labarthe, D., Mozaffarian, D. and Appel, L.J. (2010) Defining and Setting National Goals for Cardiovascular Health Promotion and Disease Reduction: The American Heart Association's Strategic Impact Goal through 2020 and beyond. Circulation, 121, 586-613. https://doi.org/10.1161/CIRCULATIONAHA.109.192703

[25] Giménez-Bastida, J.A. and Zieliński, H. (2015) Buckwheat as a Functional Food and Its Effects on Health. Journal of Agriculture and Food Chemistry, 63, 7896-7913. https://doi.org/10.1021/acs.jafc.5b02498

[26] Eggum, B.O., Kreft, I. and Javornik, B. (1980) Chemical Composition and Protein Quality of Buckwheat (Fagopyrum esculentum Moench). Plant Foods for Human Nutrition, 30, 175-179. https://doi.org/10.1007/BF01094020

[27] Bonafaccia, G., Gambelli, L., Fabjan, N. and Kreft, I. (2003) Trace Elements in Flour and Bran from Common and Tartary Buckwheat. Food Chemistry, 83, 1-5. https://doi.org/10.1016/S0308-8146(03)00228-0

[28] Dahlberg, J. (2019) The Role of Sorghum in Renewables and Biofuels. Methods in Molecular Biology, 1931, 269-277. https://doi.org/10.1007/978-1-4939-9039-9_19

[29] Thomson, J.R. (2017) What Is Sorghum? And Why Is the South So Obsessed with It. Food and Drink. https://www.huffpost.com/entry/sorghum-syrup-grain-super_n_6063016

[30] Simnadis, T.G., Tapsell, L.C. and Beck, E.J. (2016) Effect of Sorghum Consumption on Health Outcomes: A Systematic Review. Nutrition Review, 74, 690-707. https://doi.org/10.1093/nutrit/nuw036

[31] Alhassan, K., Agbenorhevi, J.K. and Asibuo, J.Y. (2017) Proximate Composition and Functional Properties of Some New Groundnut Accessions. Journal of Food Security, 5, 9-12. https://doi.org/10.12691/jfs-5-1-2

[32] Angeloni, C., Leoncini, E., Malaguti, M., Angelini, S., Hrelia, P. and Hrelia, S. (2009) Modulation of Phase II Enzymes by Sulforaphane: Implications for Its Cardioprotective Potential. Journal of Agricultural and Food Chemistry, 57, 615-622. https://doi.org/10.1021/jf900549c

[33] Amjad, A.I., Parikh, R.A., Appleman, L.J., Hahm, E.R., Singh, K. and Singh, S.V. (2015) Broccoli-Derived Sulforaphane and Chemoprevention of Prostate Cancer: From Bench to Bedside. Current Pharmacology Reports, 1, 382-390. https://doi.org/10.1007/s40495-015-0034-X

[34] Surampudi, P., Enkhmaa, B., Anuurad, E. and Berglund, L. (2016) Lipid Lowering with Soluble Dietary Fiber. Current Atherosclerosis Reports, 18, 75.

https://doi.org/10.1007/s11883-016-0624-Z

[35] Gemede, H.F., Haki, G.D., Beyene, F., Woldegiorgis, A.Z. and Rakshit, S.K. (2015) Proximate, Mineral, and Antinutrient Compositions of Indigenous Okra (Abelmoschus esculentus) Pod Accessions: Implications for Mineral Bioavailability. Food Science and Nutrition, 4, 223-233. https://doi.org/10.1002/fsn3.282

[36] Kahlon, T.S. and Smith, G.E. (2007) In Vitro Binding of Bile Acids by Okra, Beets, Asparagus, Eggplant, Turnips, Green Beans, Carrots, and Cauliflower. Food Chemistry, 103, 676-680. https://doi.org/10.1016/j.foodchem.2006.07.056

[37] Alvarez-Parrilla E., de la Rosa, L.A., Amarowicz, R. and Shahidi, F. (2011) Antioxidant Activity of Fresh and Processed Jalapeño and Serrano Peppers. Journal of Agriculture and Food Chemistry, 59, 163-173. https://doi.org/10.1021/jf103434u

[38] Ludy, M., Moore, G.E. and Mattes, R.D. (2012) The Effects of Capsaicin and Cap- 
siate on Energy Balance: Critical Review and Meta-Analyses of Studies in Humans. Chemical Senses, 37, 103-121. https://doi.org/10.1093/chemse/bjr100

[39] AOAC (2000) Official Methods of Analysis of the Association of Official Analytical Chemists. 17th Edition, The Association, Arlington.

[40] AOAC (1990) Official Methods of Analysis of the Association of Official Analytical Chemists. 15th Edition, The Association, Arlington.

[41] Kahlon, T.S., Avena-Bestillos, A. and Chiu, M.C. (2018) Gluten-Free Ancient Whole Grain Buckwheat Snacks. Nutrition and Food Science, 6, 1-6. https://doi.org/10.19080/NFSIJ.2018.06.5556687

[42] Statista (2021) Snack Food Is the U.S. https://www.srilankabusiness.com/pdf/market_study/snacks_food_in_usa_statista.p df 